\title{
The laboratory tests of hybrid layers combining hardfacing and nitriding dedicated to increase the durability of forging tools in hot forging processes
}

\begin{abstract}
In response to the growing need to use wear-resistant layers that increase durability of tools in forging processes, hybrid layers have been proposed that combine hardfacing with nitriding treatment. This article presents the results of laboratory tests of surface wear-resistant layers made with a new hybrid technology Gas-Shielded Metal Arc surfacing (hardfacing) with ZeroFlow gas nitriding. Specimens made with hardfacing or nitriding were prepared and examined. Analysis covered the thorough microstructure study, EDX chemical composition analysis and microhardness analysis. In experiment, 3 different types of nitrided layers were proposed for alpha, gamma prim and epsilon nitrides in the surface layer. The results of metallographic research in the surface layer was presented. The analysis of chemical composition in the particular overlay welds was performed to determine the content of alloying elements in the particular overlay welds. The susceptibility to nitriding of used weld materials as well as the ability to form particular types of nitrides on selected welded substrates was also tested.
\end{abstract}

Keywords: hardfacing; nitriding; surface layer

\section{Introduction}

The durability of tools used in industrial production processes is an issue that has long been devoted to a lot of attention. Hot die forging processes belong to processes in which the cost of tools is one of the main production costs, especially in the case of complex patterns whose durability is particularly low. The main reason for low durability of forging tools is extremely hard working conditions [1]. During operation, these tools are constantly exposed to destructive factors such as intense heat shocks, cyclically changing mechanical loads and intense friction at high pressures [2]. In particular, the surface layer of the tool is exposed to these factors, which is why the majority of destructive mechanisms occur in this area of the tool, so modifying the properties of the surface layer of forging tools is the most effective way to improve their durability [3]

In connection with the above, various attempts have been made to modify the surface layer of tools, i.e.: mechanical techniques (burnishing, shot peening, roll hardening), welding techniques such as thermo-chemical treatment (nitriding, nitrocarburizing) and the latest methods which include beam techniques using laser machining and hybrid methods.

Among the known and used methods of modifying the surface layer of tools, one of the oldest and most popular is the thermo-chemical treatment by nitriding. Nitriding increases the resistance of tools to abrasion, fatigue strength and increases resistance to corrosion. It has been shown that this procedure allows to improve the durability of the tools. The conducted research has shown that the nitrided layer must have a uniform and defined structure, in order to effectively improve the durability of the tool. During nitriding, a diffusion zone (a) of nitrogen ferrite with releases of carbonitrides and nitrides $\gamma^{\prime}$, is formed first, and then, depending on the process parameters, a continuous zone of nitrides and carbonitrides $\varepsilon+\gamma$ ' forms with the increasing content of nitrides $\varepsilon$. It turns out that the nitrided layers with the surface phase zone $\varepsilon$, generally have low ductility while showing high abrasion resistance, and therefore are suitable for working in conditions where there are

mgr inż. Paweł Widomski, prof. dr hab. inż. Zbigniew Gronostajski, dr inż. Marcin Kaszuba, mgr inż. Mariusz Pawełczyk - Wrocław University of Science and Technology, Poland; mgr inż. Jagoda Kowalska - SECO WARWICK 
lower dynamic loads. In turn, the layer made of carbonitrides and nitrides $y^{\prime}$,contributes to the increase of resistance to abrasion and seizure and increases resistance to corrosion. On the other hand, nitrided layers without a zone of compounds are characterized by very good fatigue strength, have a lower tendency to cracking due to thermal fatigue and are therefore suitable for working in conditions of high dynamic loads [4].

Nitriding technology, despite the fact that it has been well mastered and has been successfully used for many years, is increasingly unable to meet the expectations related to the durability of tools used in advanced, high-performance hot die forging processes. Along with the increase of the requirements for the quality of tools, it is expected that the nitriding processes enable precise regulation of the chemical composition of the nitriding atmosphere and the nitrogen potential allowing to obtain nitrided layers of any given structure. New methods of controlling nitriding processes are being developed to meet manufacturers' expectations.

An example of such a nitriding method is the Zero-Flow method developed by the Seco Warwick company, which is based on the nitriding process using a single-component atmosphere consisting only of the dissociated ammonia $\left(\mathrm{NH}_{3}\right)$ retort inside the furnace. The regulation of the chemical composition of the atmosphere in the retort, and thus the regulation of the nitrogen potential $(\mathrm{Np})$, takes place by periodically closing and opening the inflow of $\mathrm{NH}_{3}$ to the retort. The amount of $\mathrm{NH}_{3}$ introduced into the retort is controlled and regulated using gas analyzers (e.g. $\mathrm{NH}_{3}$ or $\mathrm{N}_{2}$ ). Particularly important is the fact that in the Zero-Flow method, the ammonia inflow to the retort is periodically limited to zero. This allows a significant reduction in process gas consumption compared to conventional nitriding methods, as well as a simplification of the nitriding station and the process itself, while maintaining full control of the kinetics of the layer growth [5].

In recent years, the more and more often used technology to improve durability, consisting of the modification of the surface layer, is hardfacing, in particular regenerative and preventive hardfacing. It consists of covering the forging tools with a metal layer by welding while melting the substrate. The precise metallurgical melting of the welded coating (padding weld) with the melted substrate material, whose share in the metal of the padding weld can reach up to $60 \%$, is important. The task of the padded layer is to provide the best possible exploitation properties of the surface layer, preventive action (refining) or, in the case of regeneration surfacing, restore these properties by rebuilding the surface. At present, the hardfacing carried out in forges usually takes place by available welding methods, i.e.: GTA, GMA, SSA (self-shielding wire). Previous observations of welded forging tools have shown that this can effectively increase their durability [6].

The latest solutions that increase the durability of forging tools include hybrid techniques involving the use of two or more surface engineering techniques, the most popular of which are the nitrided layer and PVD coating layer, are increasingly used [7].

Among hybrid technologies, the new solution proposed by the authors of the work is a hybrid layer created by hardfacing and nitriding. Due to the combination and interaction of two different technologies it is possible to obtain surface layer properties unattainable using these techniques separately.

The authors' research concerned the simultaneous use of hardfacing combined with later nitriding. Preliminary results showed an almost twofold increase in durability compared to standard tools used in which only one of the mentioned techniques was used [8]. In the literature available, there is little information on the feasibility of using hybrid top layers formed by combining hardfacing with nitriding to increase the durability of forging tools. However, there

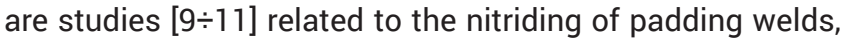
welded machine elements or even deliberate surfacing and nitriding of steel construction elements. These works indicate increased resistance to corrosion, tribological resistance and higher mechanical strength of such layers.

\section{Materials and research methodology}

The paper presents the results of laboratory tests carried out on steel samples with dimensions of $100 \times 60 \times 30 \mathrm{~mm}$ made of steel X37CrMoV5-1. Robotool 46, Castolin EnDOtec ${ }^{\circledR}$ DO*04 and Megafil A750M powder wires were used as the padding weld. The chemical composition of steel and welding wires used are presented in Table I.

The tests included hardfacing with powder wire on the surface of the prepared samples. Two layers were hardfaced immediately after each other with the preservation of defined temperatures and current-voltage parameters, whose average values are shown in Table II.

After welding, all samples were machined by milling (surface planning) to properly prepare the surface for the nitriding process. To determine the actual content of individual alloy additives in the surface layer, which is different in individual zones due to the degree of remelting and variable share of the base material and binder material in the padding weld, chemical composition analysis was performed by spectral analysis with optical emission spectrometer with spark excitation. Also microhardness distributions were determined as a function of distance from the sample surface into the material.

During the tests, three variants of nitriding were carried out to obtain on the samples 3 different nitride zones $\left(a, y^{\prime}\right.$ and $\varepsilon$ ). All types of padding weld and X37CrMoV5-1 steel were subjected to nitriding using the ZeroFlow method, each time changing the process parameters (i.e. time, temperature and nitrogen potential of the atmosphere) so as to obtain nitrided layers with the required phase structure.

As part of metallographic research, microscopic observations and microhardness measurements were made on the cross-section of the surface layer of the samples. The observation was carried out in two areas, the first area was the surface layer on the hardfaced side, while the second area was the layer on the side opposite to it, without the padding weld („raw"), where only the nitrided layer occurs.

Microscopic observations were carried out on polished and etched with $3 \%$ nital microsections using a Nikon Eclipse LV150 metallographic microscope. For each of the hardfaced samples and for the X37CrMoV5-1 steel specimen, the images were taken at a magnification of $500 x$ to assess the quality of the microstructure. On the basis of microscopic observations, the occurrence of the white layer and the nitrides grid were also checked.

In addition, from the hardfaced and nitrided side, Vickers microhardness measurements were made on a Struers Durascan 70 hardness testing machine with a load of $100 \mathrm{~g}$. For each of the paths, 10 measurement points were found at $0.04,0.08,0.12,0.14,0,16,0.18,0.20,0.22,0.36$ and 0.50 $\mathrm{mm}$ from the surface. The average microhardness distributions (shown in the graphs) were determined based on 3 measurement paths. On the basis of microhardness measurements, the depth of the nitrided layer was determined with the core hardness criterion $+50(\mathrm{HV}+50)$.

The evaluation of the obtained results of the hybrid layers was carried out in the following criteria, which are the most important from a technological point of view: lack of local 


\begin{tabular}{|c|c|c|c|c|c|c|}
\hline \multirow{2}{*}{$\begin{array}{c}\text { Tool steel/ } \\
\text { welding wire }\end{array}$} & \multicolumn{6}{|c|}{ Content of alloy additives [\%] } \\
\hline & C & Mn & Si & $\mathrm{Cr}$ & Mo & v \\
\hline X37CrMoV5-1 steel & $0.32 \div 0.42$ & $0.2 \div 0.5$ & $0.8 \div 1.2$ & $4.5 \div 5.5$ & $1.2 \div 1.5$ & $0.3 \div 0.5$ \\
\hline Wire weld metal Robotool 46 & 0.2 & 0.90 & 0.50 & $5 \div 10$ & 3.8 & 0.25 \\
\hline $\begin{array}{c}\text { Wire weld metal } \\
\text { Castolin EnDOtec }{ }^{\circledR} \text { DO*04 }\end{array}$ & \multicolumn{6}{|c|}{ The producer does not disclose the chemical composition } \\
\hline Wire weld metal Megafil A 750M & 0.3 & 1.5 & 0.4 & 5.5 & 0.5 & - \\
\hline
\end{tabular}

tempering of the material, depth of the nitrided layer, lack of a white layer on the surface, hardness in the layer cross-section. Each criterion was given a weight of 2 and the layers were assigned values of 0.1 or 2 . Thanks to this, a hybrid analysis was obtained by applying a multi-criteria analysis.

\section{Research results}

On the basis of the conducted tests, an attempt was made to assess the quality of padding welds obtained in the hardfacing process with three types of welding wire. First, microhardness in the cross-section of padding welds up to a depth of $10 \mathrm{~mm}$ from the surface was examined. These studies were related to the spectral analysis of the chemical composition made on the surface of the samples.

\section{Results of the study of hardfaced layers}

The results of the micro-hardness tests of padding welds were compared on one graph (Fig. 1). The hardness tests of padding welds revealed a decrease in hardness in the heat impact zone to the value of $350 \mathrm{HV}$, which proves the local

Table II. Parameters of welding processes

\begin{tabular}{|c|c|}
\hline Welding process & $\begin{array}{c}138 \text { (welding with powder wire } \\
\text { with a metal core) }\end{array}$ \\
\hline Dimension of the binder [mm] & 1,6 \\
\hline Current [A] & Bead number. 1-175, 2-275 \\
\hline Arc voltage [V] & Bead number. $1-21,2-29,5$ \\
\hline Type of polarity & 30 \\
\hline Hardfacing speed [cm/min] & $13 \div 20$ \\
\hline Shielding gas & $11 \div 20$ \\
\hline $\begin{array}{c}\text { Gas flow speed } \\
\text { [l/min] }\end{array}$ & \begin{tabular}{c} 
ISO $14175-\mathrm{M} 14-$ ArCO $-5 / 2$ \\
\hline $\begin{array}{c}\text { The length } \\
\text { of the free wire outlet [mm] }\end{array}$
\end{tabular} \\
\hline $\begin{array}{c}\text { Angle of welding torch } \\
\text { adjustment }\end{array}$ & $\begin{array}{c}\text { Perpendicular to the hardfaced } \\
\text { surface }\end{array}$ \\
\hline $\begin{array}{c}\left.\text { Preheat temperature [ }{ }^{\circ} \mathrm{C}\right] \\
\left.\text { Interpass temperature [ }{ }^{\circ} \mathrm{C}\right]\end{array}$ & 350 \\
\hline $\begin{array}{c}\text { Number of padding weld } \\
\text { layers }\end{array}$ & 400 \\
\hline $\begin{array}{c}\text { Thickness of the obtained } \\
\text { padding weld }\end{array}$ & 2 \\
\hline
\end{tabular}

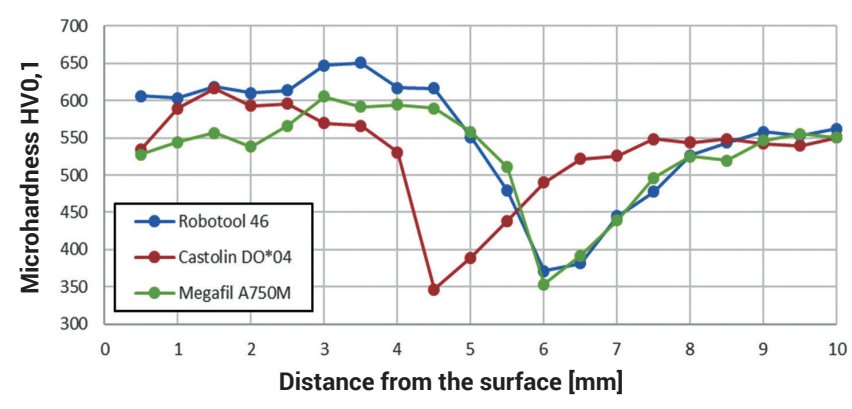

Fig. 1. Results of microhardness measurement as a function of distance from the surface

release of material at a depth of approx. $5 \div 6 \mathrm{~mm}$ (in the case of Castolin $\mathrm{DO} * 04$ this depth is slightly lower). Thus, by measuring the micro-hardness, the actual thickness of the padding weld after mechanical surface treatment was revealed, which in the case of weld metal from Robotool 46 and Megafil A750M wires is approx. $5 \mathrm{~mm}$ and for Castolin wire DO*04 is approx. $4 \mathrm{~mm}$. As in the case of the discussed samples, the depth of nitrided layers produced doesn't exceed $0.5 \mathrm{~mm}$, this phenomenon does not have a direct impact on the properties of the surface layer.

Analysis of the chemical composition showed the content of individual alloy additions and non-metallic inclusions. Examination of the padding weld made of Castolin DO*04 welding wire revealed the share of individual alloy additions not provided by the manufacturer and showed that it deviates significantly from the composition of the base (tool steel) in terms of increased chromium and molybdenum content and lower manganese content. With reference to Table I, the data presented in Table III confirm that the chemical composition of Robotool 46 welding wire is similar to that of $\mathrm{X} 37 \mathrm{Cr}$ MoV5-1 steel.

The Megafil A750M wire has a much higher Mo content which can inhibit the drop in hardness during tempering as a result of contact with the hot material during forging.

\section{Results of metallographic studies of nitrided layers}

Figures $2 \div 4$ present the comparison of the microstructure of nitrided layers to the zone $a, y^{\prime}$ and $\varepsilon$, obtained for 4 different substrate materials listed in Table I.

The results of metallographic investigations of nitrided layers presented in Figure 2 revealed different susceptibility of padding welds to diffusion of nitrogen deep into the surface during the nitriding process. As a reference point, microscopic observations of the nitrided layer obtained on the X37CrMoV5-1 steel specimen were accepted. The nitrided layers obtained on the remaining samples on non-welded surfaces were of the same depth as the reference sample and reached approx. $0.13 \mathrm{~mm}$ after the processes for the zone $a$ and $\gamma$, and approx. $0.15 \mathrm{~mm}$ after the process into zone $\varepsilon$. 
Table III. Results of spectral analysis of the chemical composition of hardfaced layers

\begin{tabular}{|c|c|c|c|c|c|c|c|c|c|}
\hline \multirow{2}{*}{ Padding weld } & \multicolumn{9}{|c|}{ Content of alloy additives [\%] } \\
\hline & C & Mn & Si & $\mathrm{Cr}$ & Mo & v & S & $\mathbf{P}$ & $\mathrm{Ni}$ \\
\hline Made of Robotool 46 wire & 0.137 & 1.08 & 0.65 & 6.12 & 0.90 & 0.15 & 0.008 & 0.008 & 0.05 \\
\hline Made of Castolin EnDOtec ${ }^{\circledR} \mathrm{DO} * 04$ wire & 0.056 & 0.27 & 0.55 & 10.26 & 2.01 & 0.18 & 0.006 & 0.005 & 0.49 \\
\hline Made of Megafil A 750M wire & 0.034 & 0.92 & 0.49 & 4.95 & 3.39 & 0.09 & 0.019 & 0.006 & 0.27 \\
\hline
\end{tabular}
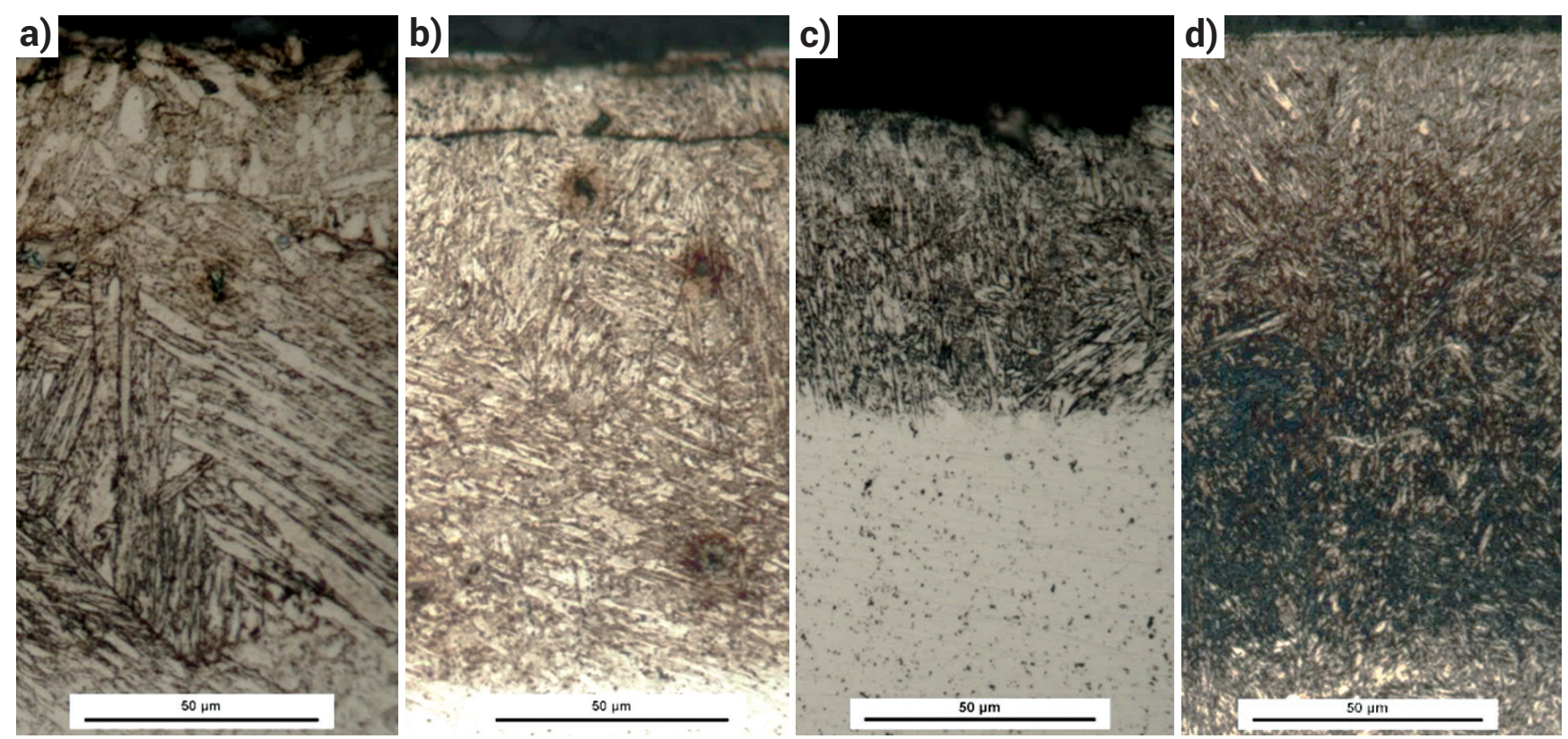

Fig. 2. The nitrided layer performed for the a zone on the substrate of: a) X37CrMoV5-1 steel; b) Robotool 46 wire hardfaced on X37CrMoV5-1 steel; c) Castolin DO*04 wire hardfaced on X37CrMoV5-1; d) Megafil A750M wire hardfaced on X37CrMoV5-1 steel
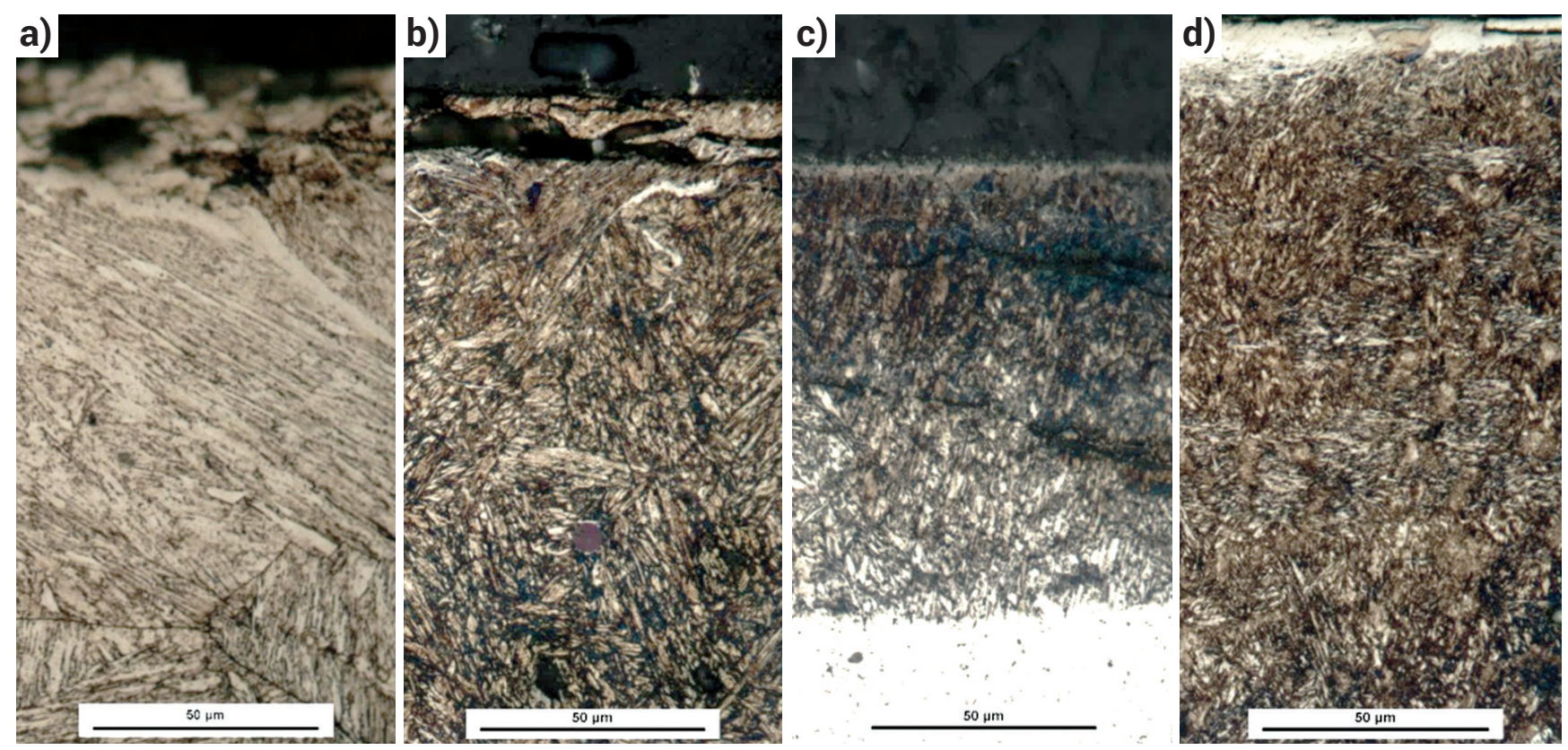

Fig. 3. The nitrided layer performed for the $\mathrm{y}^{\prime}$ zone on the substrate of: a) X37CrMoV5-1 steel; b) Robotool 46 wire hardfaced on X37CrMoV5-1 steel; c) Castolin DO*04 wire hardfaced on X37CrMoV5-1; d) Megafil A750M wire hardfaced on X37CrMoV5-1 steel

While none of the padding welds completely inhibited nitrogen diffusion, it can be clearly seen that in the case of the Castolin $\mathrm{DO} * 04$ hardfaced sample, the depth of the nitrided layer is much lower than in the other samples (about 2 times). The reduced susceptibility to diffusion of nitrogen in the Castolin $\mathrm{DO} * 04$ wire filler can be explained by the high chromium content of $10 \%$ (based on the data in Table III), whose content in steels significantly delays the diffusion of nitrogen [12].
For the Robotool 46 and Megafil A750M hardfaced samples, the depth of the nitrided layer on the padding weld surface equaled the depth of the nitrided layer on the surface free of padding weld. It is worth noting that on the sample Megafil A750M as the only one a white layer was formed after the $Y^{\prime}$ and $\varepsilon$ processes, while on the Robotool 46 and Castolin $\mathrm{DO} * 04$ hardfaced samples no white layers were observed from the surface, even if it appeared on other surfaces. 

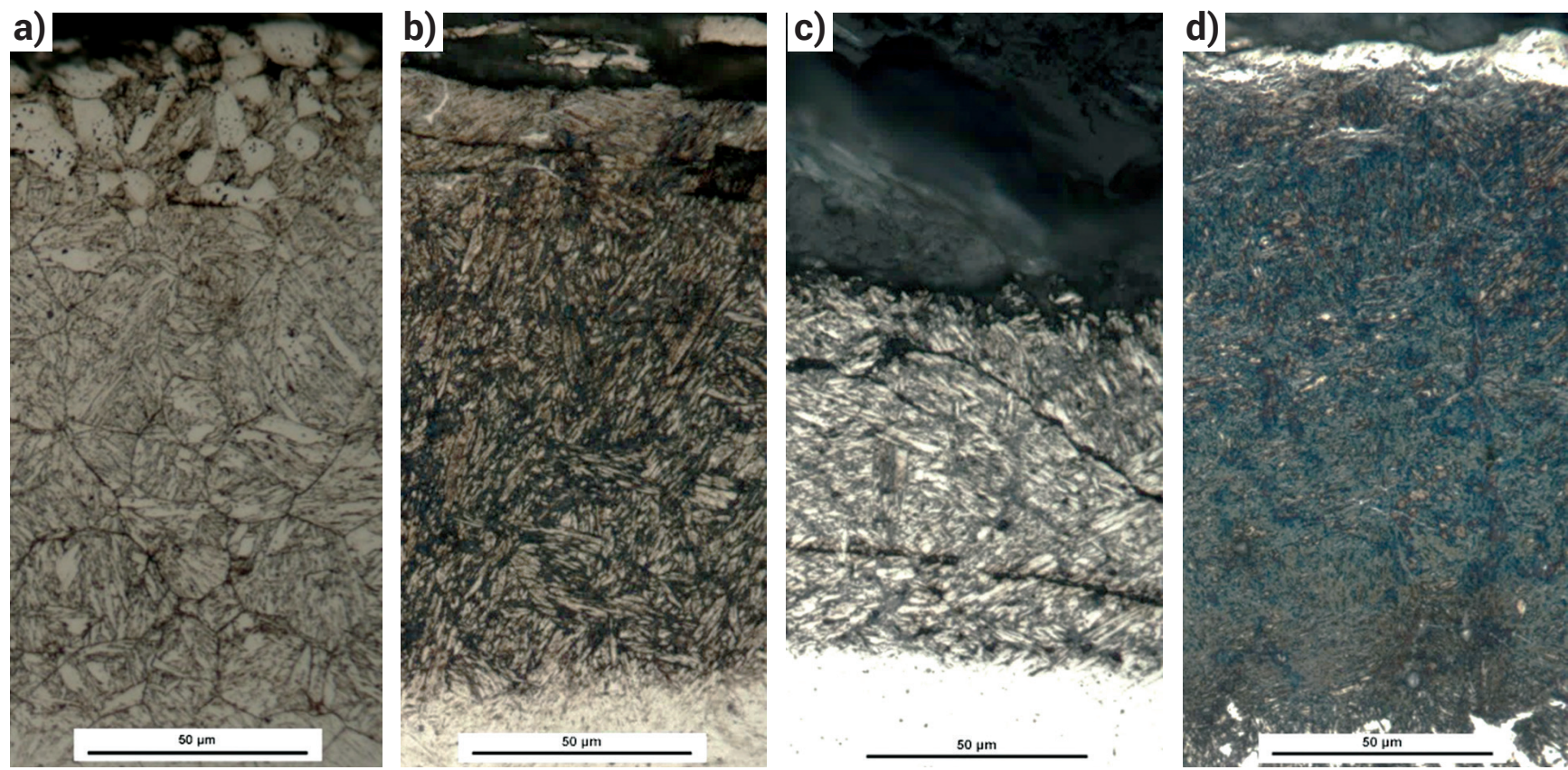

Fig. 4. The nitrided layer performed for the $\varepsilon$ zone on the substrate of: a) X37CrMoV5-1 steel; b) Robotool 46 wire hardfaced on X37CrMoV5-1 steel; c) Castolin D0*04 wire hardfaced on X37CrMoV5-1; d) Megafil A750M wire hardfaced on X37CrMoV5-1 steel

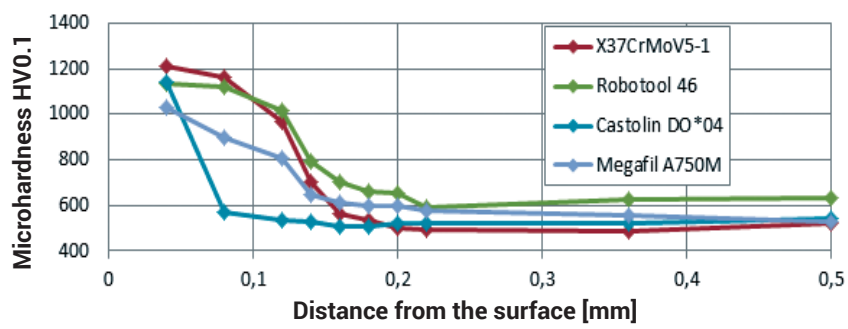

Fig. 5. Results of microhardness measurement of nitrided layers as a function of distance from the surface for all tested hardfaced layers and tool steels, after nitriding for the a zone

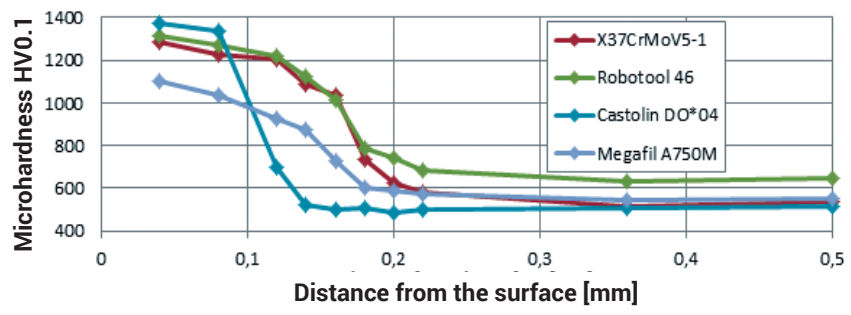

Fig. 6. Results of microhardness measurement of nitrided layers as a function of distance from the surface for all tested hardfaced layers and tool steels, after nitriding for the $y^{\prime}$ zone

Regardless of the type of padding weld used, all nitrided layers produced on the hardfaced surfaces are of good quality, uniform and free of nitrides.

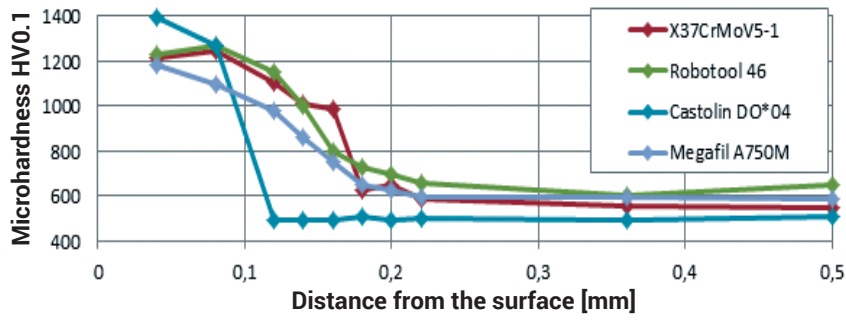

Fig. 7. Results of microhardness measurement of nitrided layers as a function of distance from the surface for all tested hardfaced layers and tool steels, after nitriding for the $\varepsilon$ zone

\section{Results of microhardness analysis in nitrided layers}

Measurements of microhardness showed an increase in hardness at the depth of approx. $0.13 \mathrm{~mm}$ after the processes for the zone $a$ and $\gamma^{\prime}$ and approx. $0.15 \mathrm{~mm}$ after the process for the $\varepsilon$ zone for a reference sample and hardfaced samples Robotool 46 and Megafil A750M, thus confirming the previously performed microscopic observations. In addition, as was the case during microscopic observations, the depth of the nitrided layer on the Castolin DO*04 hardfaced sample can be clearly seen, regardless of the process carried out, which can be explained by the high chromium content in this type of padding weld. Additional information resulting from the prepared microhardness distributions is the reduction of nitrided layer hardness on samples hardfaced with Megafil A750M.

\section{Discussion of the results and summary}

Table IV provides an assessment of individual nitrided layers by giving a point weight within selected criteria. Based on this assessment, it can be concluded that the best results (in terms of the expected properties of the surface layer) were obtained for the Robotool 46 hardfaced sample - the obtained layers are similar in depth to the layers obtained on X37CrMoV5-1 steel, there was also no decrease in hardness on the cross-section of the layer, a white layer on the surface. 
Table IV. Assumed evaluation criteria for the tested samples

\begin{tabular}{|c|c|c|c|}
\hline & Robotool 46 & Castolin D0*04 & Megafil A750M \\
\hline No local material release & 2 & 0 & 2 \\
\hline Depth of the nitrided layer & 2 & 1 & 2 \\
\hline No white layer on the surface & 2 & 2 & 1 \\
\hline Hardness in the cross section of the layer & 2 & $\mathbf{3}$ & 1 \\
\hline SUM & $\mathbf{8}$ & $\mathbf{6}$ \\
\hline
\end{tabular}

On the basis of the quality assessment of the obtained layers shown in Table IV, it can be concluded that the layer hardfaced with Robotool 46 wire has the highest susceptibility to nitriding and is therefore the most suitable for creating hybrid layers that combine these two methods of surface layer processing. Megafil A750M wire padding weld allows to obtain nitrided layer with lower depth of diffusion layer and lower hardness in the surface layer with additional presence of hard and brittle white nitrides on the surface. Although this is unfavorable in terms of the use on the surface of forging dies, it can be used in other applications, e.g. on aluminum extrusion dies. Castolin $\mathrm{DO} * 04$ wire padding weld is clearly not suitable for subsequent nitriding because it is not susceptible enough to nitrogen diffusion, which is limited due to the high chromium content of $10 \%$.

The study was financed by the National Science Centre Poland, grant no 017/25/N/ST8/02792

\section{References}

[1] M. Zwierzchowski, Factors Affecting the Wear Resistance of Forging Tools, Archives of Metallurgy and Materials (2017), vol. 62 (3), 1567-1576, https://doi.org/10.1515/amm-2017-0240.

[2] C. Choi, A. Groseclose, T. Altan, Estimation of plastic deformation and abrasive wear in warm forging dies, Journal of Materials Processing Technology (2012), vol. 212 (8), 1742-1752.

[3] M. Bayramoglu, H. Polat, N. Geren, Cost and performance evaluation of different surface treated dies for hot forging process, Journal of Materials Processing Technology (2008), vol. 205 (1-3), 394-403, https://doi. org/10.1016/j.jmatprotec.2007.11.256.

[4] L. Małdzinski, W. Liliental, G. Tymowski, J. Tacikowski, New possibilities for controlling gas nitriding process by simulation of growth kinetics of nitride layers, Surface Engineering (1999), vol. 15 (5), 377-384, doi: 10.1179/026708499101516740.

[5] L. Małdziński, K. Ostrowska, P. Okoniewicz, Controlled ZeroFlow gas nitriding as a method increasing the durability of dies for hot extrusion of aluminum profiles, Metal Forming=Obróbka Plastyczna Metali (2014), vol. XXV (3), 169-183.

[6] V. Lazić, D. Arsić, R. Nikolić, Reparation of damaged forging dies by hard facing (HF) technology, Production Engineering Archives (2015), vol. 6 (1), 26-29, DOI: 10.30657/pea.2017.06.07.
[7] M. Hawryluk, Z. Gronostajski, P. Widomski, Influence of the application of a $\mathrm{PN}+\mathrm{CrN}$ hybrid layer on improvement of the lifetime of hot forging tools, Journal of Materials Processing Technology (2018), vol. 258, 226-238. https://doi.org/10.1016/j.jmatprotec.2018.03.029.

[8] Z. Gronostajski, P. Widomski, M. Kaszuba, M. Zwierzchowski, M. Hawryluk, Influence of both hardfaced and nitrided layers on the durability of hot forging tools, Surface Innovations (2018), vol. 6 (4-5), 301-310, https://doi.org/10.1680/jsuin.18.00021.

[9] H. Yokoyama, M. lio, (2015) Engine Valve Japanese Patent JP 2012077998 W 20121030, EP 2915965 A1.

[10] J. Alphonsa, B.A. Padsala, B.J. Chauhan, Plasma nitriding on welded joints of AISI 304 stainless steel. Surface and Coatings Technology 2013, vol. 228 (Supl1), S306-S311, https://doi.org/10.1016/j.surfcoat.2012.05.113.

[11] V.I. Lukin, V.G. Kovalchuk, Y.V. Golev, I.S. Mazalov, I.I. Ovchenkova, Welding a creep-resisting $\mathrm{Ni}-\mathrm{Co}-\mathrm{Cr}$ (VZh171) alloy strengthened by nitriding, Welding International (2013), vol. 27 (11), 897-902, DOI: 10.1080/09507116.2013.796642.

[12] L. Berkowski, Wpływ struktury na skutki azotowania chromowych stali ledeburytycznych, część 1: Informacje o materiale do badań, Obróbka Plastyczna Metali (2005), vol. 1 (5) 